\title{
ARTICLE
}

Received 22 Jul 2014 | Accepted 13 May 2015 | Published 23 Jun $2015 \quad$ DOl: 10.1038/ncomms8466

\section{A metabolic stress-inducible miR-34a-HNF4 $\alpha$ pathway regulates lipid and lipoprotein metabolism}

Yang $\mathrm{Xu}^{1, \star}$, Munaf Zalzalal, ${ }^{1, \star}$, Jiesi $\mathrm{Xu}^{1}$, Yuanyuan $\mathrm{Li}^{1}$, Liya Yin ${ }^{1} \&$ Yanqiao Zhang ${ }^{1}$

Non-alcoholic fatty liver disease (NAFLD) is one of the most common liver diseases, but its underlying mechanism is poorly understood. Here we show that hepatocyte nuclear factor $4 \alpha(H N F 4 \alpha)$, a liver-enriched nuclear hormone receptor, is markedly inhibited, whereas miR-34a is highly induced in patients with non-alcoholic steatohepatitis, diabetic mice and mice fed a high-fat diet. miR-34a is essential for HNF4 $\alpha$ expression and regulates triglyceride accumulation in human and murine hepatocytes. miR-34a inhibits very low-density lipoprotein secretion and promotes liver steatosis and hypolipidemia in an HNF4 $\alpha$-dependent manner. As a result, increased miR-34a or reduced HNF $4 \alpha$ expression in the liver attenuates the development of atherosclerosis in Apoe ${ }^{-/-}$or $\mathrm{Ldll}^{-/-}$mice. These data indicate that the miR-34a-HNF $4 \alpha$ pathway is activated under common conditions of metabolic stress and may have a role in the pathogenesis of NAFLD and in regulating plasma lipoprotein metabolism. Targeting this pathway may represent a novel approach for the treatment of NAFLD.

\footnotetext{
${ }^{1}$ Department of Integrative Medical Sciences, Northeast Ohio Medical University, Rootstown, Ohio 44272, USA. * These authors contributed equally to this work. Correspondence and requests for materials should be addressed to Y.Z. (email: yzhang@neomed.edu).
} 
O besity, diabetes and insulin resistance are common risk factors for non-alcoholic fatty liver disease (NAFLD) $)^{1-3}$, one of the most common liver diseases worldwide. In the United States, up to $25 \%$ of the population have NAFLD ${ }^{4,5}$. NAFLD initiates from simple steatosis, which may progress to non-alcoholic steatohepatitis (NASH) after multiple 'hits', including inflammatory mediators, reactive oxygen species (ROS), and so on ${ }^{4,6,7}$. NASH may further progress to liver cirrhosis and hepatocellular carcinoma. So far, the mechanism underlying the pathogenesis of NAFLD is poorly understood. Therefore, current treatment of NAFLD is limited to management of associated syndrome, such as diabetes and obesity ${ }^{8,9}$.

Hepatocyte nuclear factor $4 \alpha$ (HNF4 $\alpha)$ is a nuclear hormone receptor that plays an important role in both development and adult physiology. It is highly expressed in the liver, with lower levels in the kidney, intestine and pancreatic $\beta$ cells $^{10,11}$. HNF $4 \alpha$ has a highly conserved DNA binding domain and a ligand-binding domain. Structural analysis of HNF4 $\alpha$ indicates that $\mathrm{C} 14-\mathrm{C} 18$ long-chain fatty acids are tightly bound to the hydrophobic pocket of HNF $4 \alpha$ and could not be dissociated from the receptor under non-denaturing conditions ${ }^{12,13}$. As such, HNF4 $\alpha$ is constitutively active.

HNF $4 \alpha$ controls the basal expression of many genes involved in bile acid, lipid, glucose and drug metabolism. Loss-of-function mutations in human HNF4 $\alpha$ cause maturity-onset diabetes of the young type 1 (MODY1), characterized by autosomal dominant inheritance, early-onset diabetes and pancreatic $\beta$-cell dysfunction ${ }^{14}$. The diabetes phenotype appears to result from reduced glucose-stimulated insulin secretion in the pancreas ${ }^{15}$. In addition to the diabetes phenotype, patients with MODY1 also have decreased plasma triglyceride (TG) and cholesterol levels ${ }^{16-18}$, likely as a result of impaired very low-density lipoprotein (VLDL) secretion in the liver ${ }^{19}$. Consistent with the reduced VLDL secretion, we and others have shown that loss of hepatic HNF4 $\alpha$ results in fatty liver and hypolipidemia in mice ${ }^{19,20}$

MicroRNAs (miRNAs) are small non-coding RNA molecules that regulate gene expression post-transcriptionally via binding to the $3^{\prime}$-untranslated region ( $3^{\prime} \mathrm{UTR}$ ) of mRNA. miRNAs have emerged as important regulators of cell proliferation, inflammation and metabolism. Recent studies have shown that hepatic miRNAs may have an important impact on lipid and lipoprotein metabolism ${ }^{21-23}$.

In this report, we investigate the role of the miR-34a-HNF4 $\alpha$ pathway in the pathogenesis of human NAFLD and in plasma lipid and lipoprotein metabolism. Our data show that this pathway is activated in both NASH patients and diabetic or high-fat diet (HFD)-fed mice. We then investigate whether and how this pathway regulates hepatic and plasma lipid and/or lipoprotein metabolism. Finally, we explore which metabolic cues trigger the activation of this pathway. Our data suggest that the miR-34a-HNF4 $\alpha$ pathway may be an attractive target for treatment of human NAFLD.

\section{Results}

Inverse regulation of HNF4 $\alpha$ and miR-34a expression in vivo. We and others have previously shown that loss of hepatic HNF $4 \alpha$ causes fatty liver in mice ${ }^{19,20}$. As HNF $4 \alpha$ is highly conserved between humans and rodents, we explored the role of HNF $4 \alpha$ in the development of human NAFLD. As compared with the normal subjects, NASH patients had increased levels of hepatic TG (Fig. 1a) and cholesterol (Fig. 1b). Remarkably, hepatic $H N F 4 \alpha$ mRNA levels were reduced by $80 \%$ (Fig. 1c) and HNF $4 \alpha$ protein levels were almost undetectable (Fig. 1d and
Supplementary Fig. 1a) in NASH patients. Consistent with a marked reduction in hepatic HNF4 $\alpha$ expression, a number of HNF4 $\alpha$ target genes were also significantly reduced in NASH patients (Supplementary Table 1). miRNAs have been shown to play a role in the development of NAFLD ${ }^{24,25}$. In the livers of NASH patients, $m i R-34 a$ (Fig. 1e), but not $m i R-19 b$ or $m i R-27 b$ (Supplementary Fig. 1b), was induced by $>2$-fold.

NAFLD is often associated with obesity, diabetes and insulin resistance. Therefore, we investigated hepatic expression of HNF4 $\alpha$ and miR-34a in diabetes and HFD-induced obesity. In $o b / o b$ or $d b / d b$ mice (type 2 diabetes models), streptozotocin (STZ)-treated mice (a type 1 diabetes model), HFD-fed mice or high-fat/high-cholesterol (HFHC) diet-fed mice, hepatic HNF4 $\alpha$ protein levels were decreased by $75-85 \%$ (Fig. 1f-h and Supplementary Fig. 1c), whereas hepatic miR-34a levels were induced by up to 10 -fold (Fig. 1i-l). In these mice, hepatic mRNA levels of $H n f 4 \alpha$ (Supplementary Fig. 1d) or some Hnf4 $\alpha$ target genes (Supplementary Table 2) were reduced or unchanged and hepatic miR-19b or miR-27b expression did not alter (Supplementary Fig. 1e). Finally, the data from Northern blot assays confirmed that hepatic $m i R-34 a$ was overexpressed in these models (Supplementary Fig. 2a-c). Together, these data indicate that hepatic HNF4 $\alpha$ and miR-34a are inversely regulated in response to common metabolic stress.

miR-34a regulates HNF4 $\alpha$ expression and lipid metabolism. To determine whether miR-34a regulates HNF4 $\alpha$ expression and/or lipid metabolism, we injected adenoviruses expressing miR-34a (Ad-miR-34a) or Ad-empty (control) to C57BL/6 mice. Overexpression of miR-34a reduced plasma TG (Fig. 2a) and cholesterol (Fig. 2b) levels, increased hepatic TG levels by $>2$-fold (Fig. 2c) but had no effect on hepatic cholesterol levels (Supplementary Fig. 3). Overexpression of $m i R-34 a$ also significantly reduced hepatic $H n f 4 \alpha$ mRNA levels by $40 \%$ (Fig. 2d) and HNF4 $\alpha$ protein levels by $>75 \%$ (Fig. 2e,f). Consistent with the gain-of-function data, $m i R-34 a^{-1-}$ mice had increased plasma levels of TG (Fig. 2g) and cholesterol (Fig. 2h), decreased hepatic TG levels (Fig. 2i) and a 3.6-fold increase in hepatic HNF4 $\alpha$ protein levels (Fig. 2j,k). A $>3$-fold increase in hepatic HNF4 $\alpha$ protein levels was also observed in chow- or HFD-fed $m i R-34 a^{-1-}$ mice (Supplementary Fig. 4a-d). When $o b / o b$ mice or HFD-fed mice were treated with an miR-34a antagomir, hepatic miR-34a levels were reduced by $84 \%$ and $\mathrm{HNF} 4 \alpha$ protein levels were increased by $>2$-fold (Fig. 2l,m and Supplementary Fig. 5a-d). These gain- and loss-of-function data demonstrate that miR-34a regulates lipid metabolism and hepatic HNF4 $\alpha$ expression in mice.

In HepG2 cells, a human hepatoma cell line, overexpression of miR-34a reduced $\mathrm{HNF} 4 \alpha$ protein levels by $66 \%$, whereas inhibition of miR-34a expression by anti-miR-34a increased HNF $4 \alpha$ expression by 2.2 -fold (Fig. 2n,o). Consistent with a role of miR-34a in regulating lipid metabolism in mice, overexpression of miR-34a increased TG accumulation in HepG2 cells (Fig. 2p,q). Thus, the data of Fig. 2 demonstrate that miR-34a regulates HNF4 $\alpha$ expression and lipid metabolism in both human and mouse hepatocytes.

miR-34a regulates lipid metabolism by inhibition of HNF4 $\alpha$. To determine how miR-34a regulates lipid metabolism, we analysed hepatic gene expression. $\mathrm{miR}-34 \mathrm{a}$ inhibited a number of genes involved in lipid metabolism, including $H n f 4 \alpha$, microsomal triglyceride transfer protein $(M t p), A p o B$, sterol regulatory element-binding protein 1c (Srebp-1c), acetyl-CoA carboxylase 1 (Acc1), Acc2 and HMG-CoA reductase (Hmgcr) (Fig. 3a). 
a
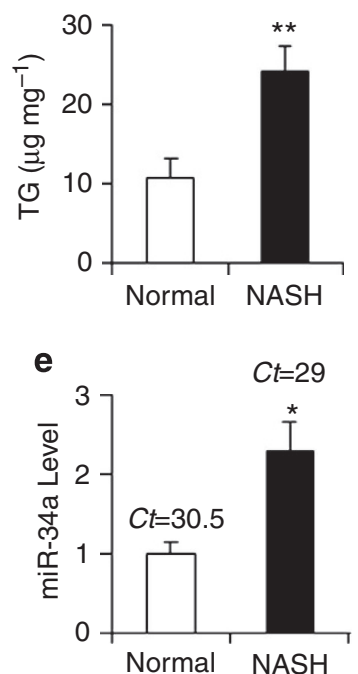

b

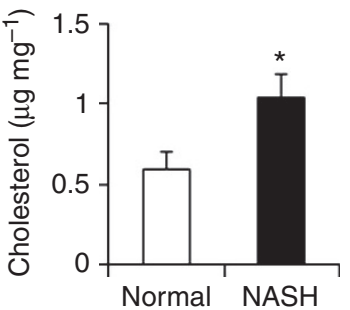

C

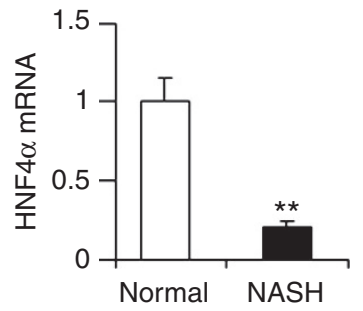

d

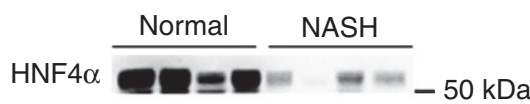

$\beta$-Actin - - $-37 \mathrm{kDa}$

g

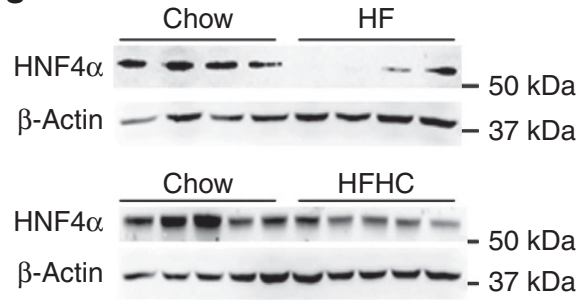

h HNF4 $\alpha$ protein
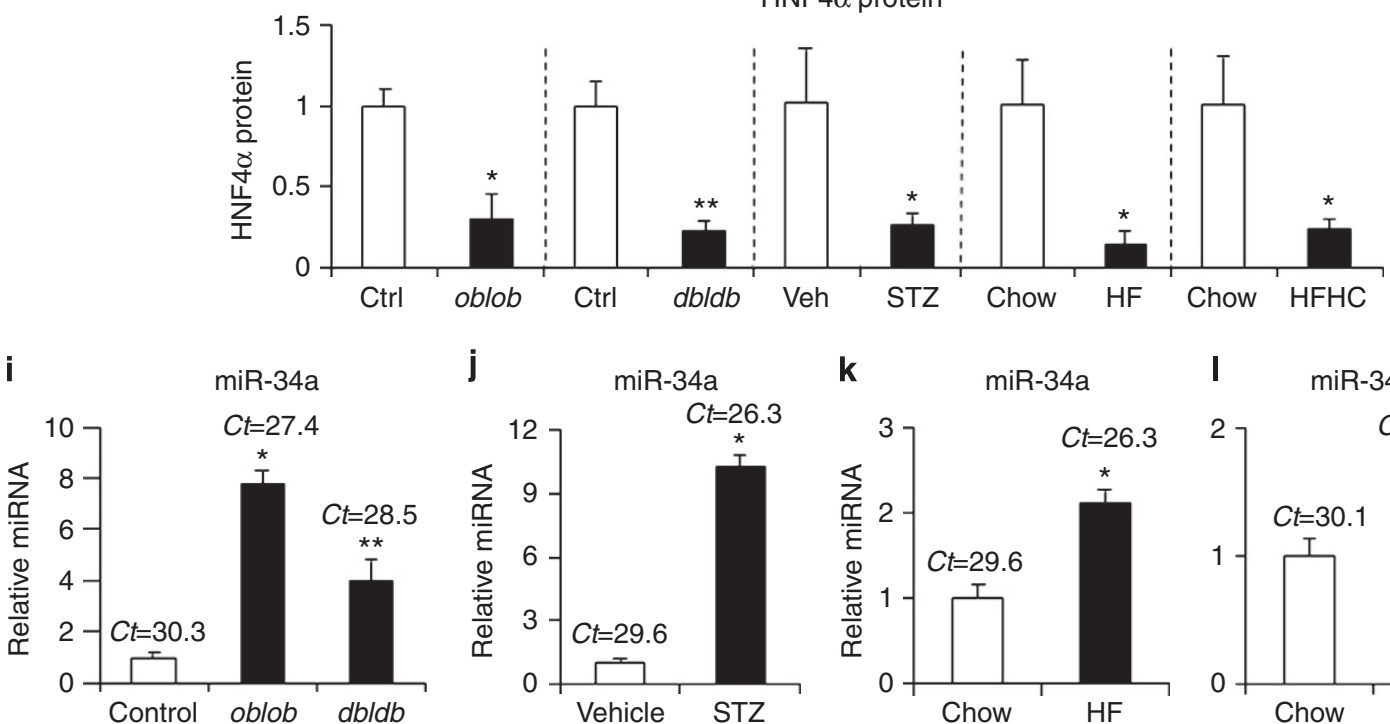

k

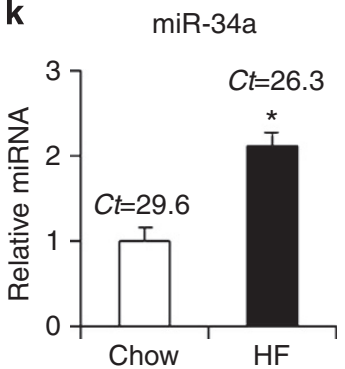

I miR-34a

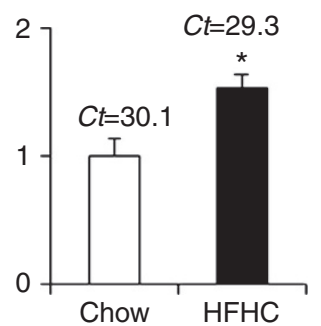

Figure 1 | Hepatic HNF4 $\alpha$ and miR-34a expression is inversely regulated in NASH patients and diabetic or HFD-fed mice. (a-e) Hepatic levels of TG (a) cholesterol (b) Hnf $4 \alpha$ mRNA (c) HNF $4 \alpha$ protein (d) and miR-34a (e) were determined in normal individuals or NASH patients $(n=8)$. (f-h) Hepatic HNF $4 \alpha$ protein levels were determined using western blots in diabetic ob/ob or $d b / d b$ mice $(\mathbf{f} ; n=5)$ or STZ-treated mice $(\mathbf{f} ; n=6)$, high-fat diet (HFD)-fed mice $(\mathbf{g} ; n=5)$ or high-fat, high-cholesterol (HFHC) diet-fed mice $(\mathbf{g} ; n=8)$. Protein levels were quantified by ImageJ $(\mathbf{h})$. (i-I) Hepatic miR-34a levels were quantified in $o b / o b$ or $d b / d b$ mice (i) STZ-treated mice (j) HFD-fed mice (k) or HFHC diet-fed mice (I). Results are shown as mean \pm s.e.m. Two-sided Student's $t$-test was performed. ${ }^{\star} P<0.05$. ${ }^{\star \star} P<0.01$.

miR-34a also reduced MTP and ApoB protein levels (Fig. 3b,c and Supplementary Fig. 6a) and MTP activity (Supplementary Fig. 6b). In contrast, loss of miR-34a increased MTP activity (Supplementary Fig. 6c). Consistent with the latter data, miR-34a inhibited VLDL secretion (Fig. 3d). Interestingly, overexpression or loss of miR-34a had no effect on de novo lipogenesis (Supplementary Fig. 7).

A deficiency in hepatic HNF4 $\alpha$ causes fatty liver and hypolipidemia by reducing VLDL secretion ${ }^{20,21}$. The data of Figs 2 and 3a-d suggest that miR-34a regulates lipid metabolism likely through inhibition of HNF4 $\alpha$. To test this hypothesis, we overexpressed $H n f 4 \alpha$ in mice infected with Ad-miR-34a to normalize hepatic HNF4 $\alpha$ protein expression to the levels seen in the control mice (Fig. 3e). Hepatic overexpression of $m i R-34 a$ reduced plasma levels of TG (Fig. 3f) and cholesterol
(Fig. 3g) and increased hepatic TG levels (Fig. 3h) in the control mice. However, these changes were abolished when hepatic HNF4 $\alpha$ protein expression was normalized (Fig. 3f-h). These data demonstrate that miR-34a regulates hepatic and plasma lipid metabolism through inhibition of hepatic HNF $4 \alpha$.

To understand how miR-34a regulates HNF4 $\alpha$ expression, we investigated whether miR-34a binds to the $3^{\prime} \mathrm{UTR}$ of $H N F 4 \alpha$. There are two highly conserved miR-34a binding sites in both human and murine $3^{\prime}$ UTRs of $H N F 4 \alpha$ (Supplementary Fig. 8a,b). As shown in Fig. 3i, an miR-34a mimic significantly repressed the activity of a luciferase promoter linked to the $H n f 4 \alpha 3^{\prime} \mathrm{UTR}$, and this repression was abolished when the second binding site for $m i R-34 a$ (mutB) was mutated. To confirm the in vitro data, we overexpressed $H n f 4 \alpha$ coding region plus wild type or mutant 
a

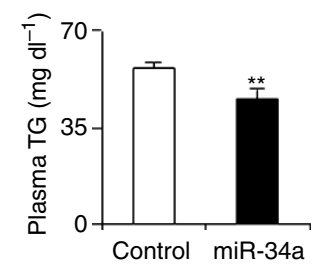

e

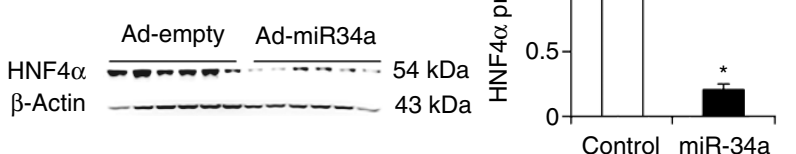

i

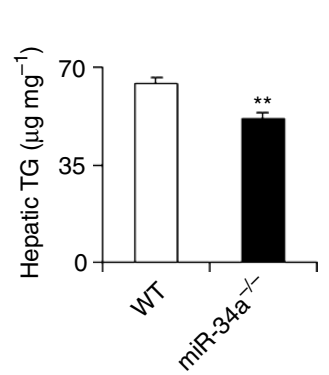

b

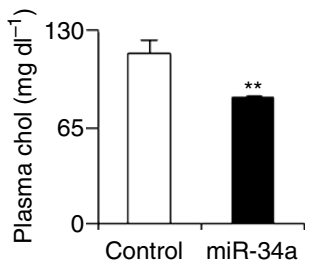

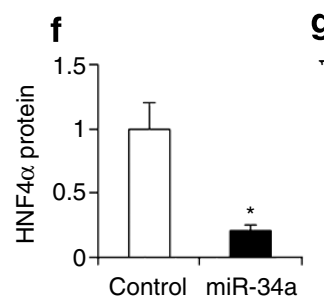

j

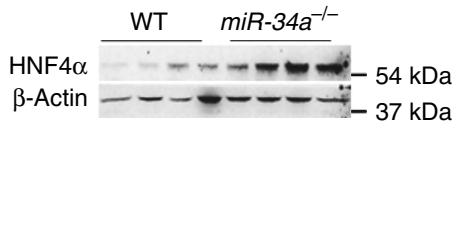

C

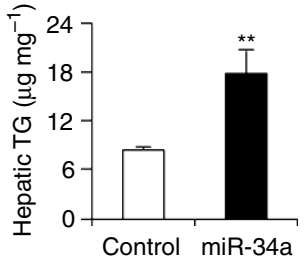

d

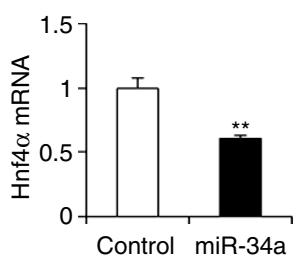

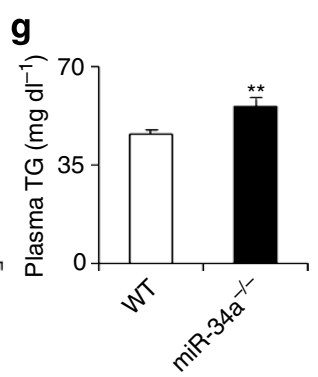

$\mathbf{k}$

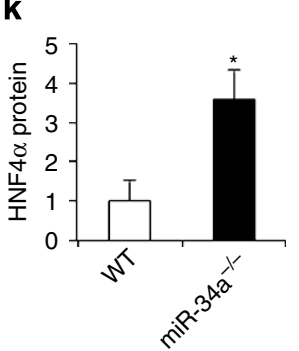

h

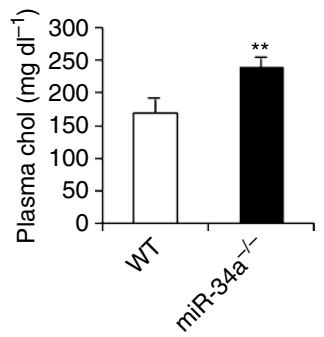

I

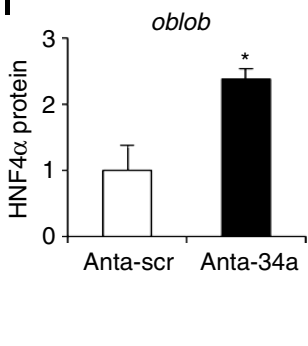

m

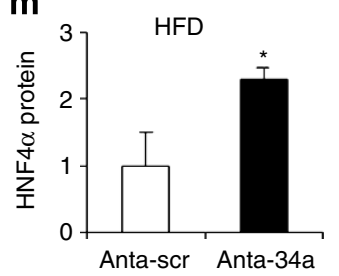

n

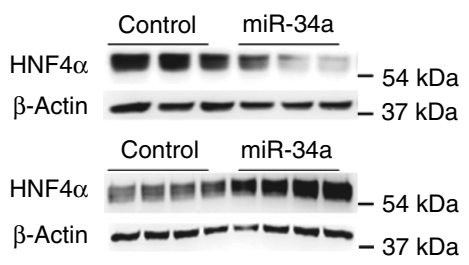

o

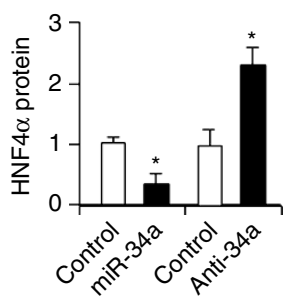

p Control

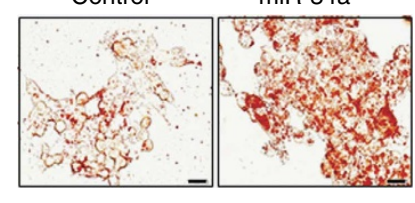

9

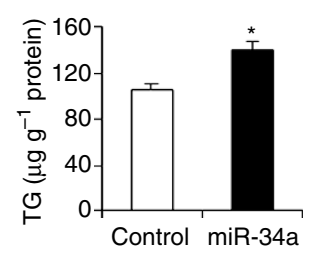

Figure 2 | miR-34a regulates lipid metabolism and inhibits HNF4 $\alpha$ expression in mice and HepG2 cells. (a-f) C57BL/6 mice were injected i.v. with either Ad-empty (control) or Ad-miR-34a (miR-34a) ( $n=6$ ). After 7 days, plasma TG (a) cholesterol (chol; b) and hepatic TG (c) levels were determined. Hepatic $H n f 4 \alpha$ mRNA level was quantified by qRT-PCR (d). Hepatic protein levels were determined by western blots (e) and then quantified (f). (g-k) Wild-type and miR-34a- / - mice were fed a Western diet for 12 weeks $(n=5)$. Plasma TG $(\mathbf{g})$ plasma cholesterol $(\mathbf{h})$ and hepatic TG levels $(\mathbf{I})$ were determined. Hepatic protein levels were determined by western blotting (j) and HNF4 $\alpha$ protein levels quantified (k). (I,m) ob/ob mice (I) or HFD-fed mice (m) were injected i.v. with anta-scr (scramble antagomir) or anta-miR-34a (miR-34a antagomir) once every 6 days $\left(10 \mathrm{mg} \mathrm{kg}^{-1}\right)(n=4-5)$. After three injections, hepatic HNF4 $\alpha$ protein levels were determined. (n,o) HepG2 cells were treated with Ad-empty (control), Ad-miR-34a or Ad-anti-miR-34a (anti-miR-34a). After 48 h, protein levels were determined by western blotting $(\mathbf{n})$ and then quantified $(\mathbf{o})(n=3)$. (p, $\mathbf{q})$ HepG2 cells were infected with Ad-empty or Ad-miR-34a for $48 \mathrm{~h}$. Neutral lipids were stained by oil red $O(\mathbf{p})$ and TG levels quantified $(\mathbf{q})(n=6)$. The transfection assays were repeated once and similar results were obtained. Scale bar, $20 \mu \mathrm{m}$. Values are expressed as mean \pm s.e.m. Two-sided Student's $t$-test was performed. ${ }^{\star} P<0.05$, ${ }^{\star \star} P<0.01$.

$3^{\prime} \mathrm{UTR}$ in liver-specific $H n f 4 \alpha^{-1}$ mice. Overexpression of $m i R$ $34 a$ markedly reduced exogenous $\mathrm{HNF} 4 \alpha$ protein levels when the $H n f 4 \alpha$ coding region was linked to the wild-type $3^{\prime}$ UTR or $3^{\prime}$ UTR with mutations in first binding site for miR-34a (mutA), and this reduction was abolished when the $H n f 4 \alpha$ coding region was linked to $3^{\prime} \mathrm{UTR}$ with mutB (Fig. 3j). Thus, our in vitro and in vivo data demonstrate that $m i R-34 a$ inhibits $H n f 4 \alpha$ expression through binding to the second binding site of the $3^{\prime} \mathrm{UTR}$. 
a

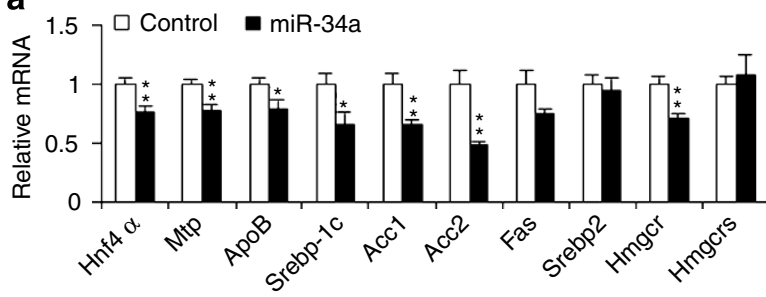

b

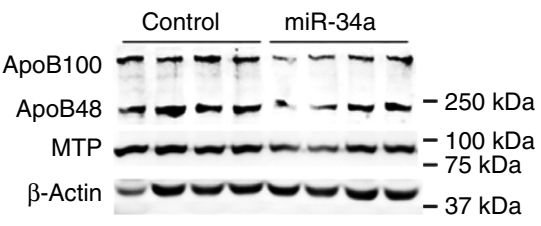

C

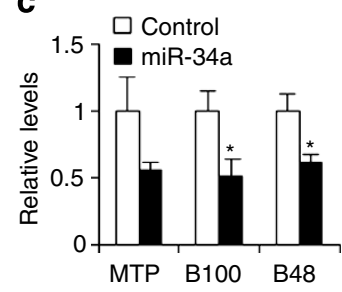

g

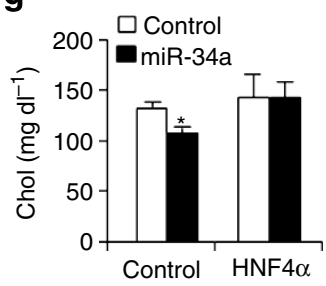

d

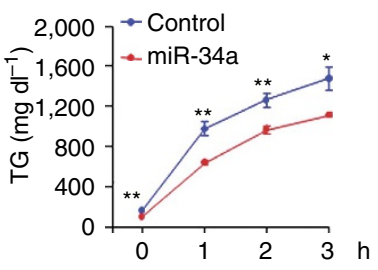

e

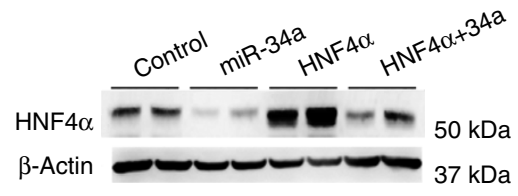

f

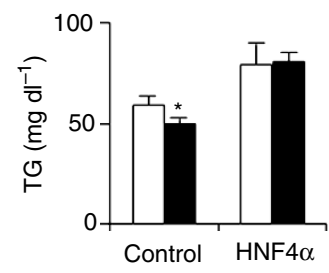

h

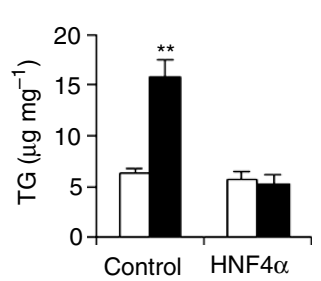

i

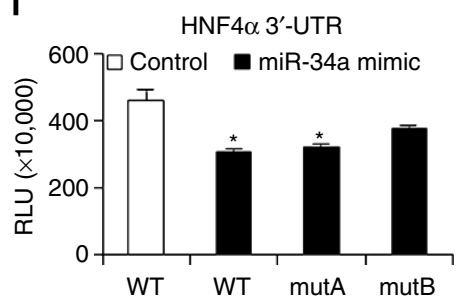

j

Figure 3 | miR-34a regulation of VLDL secretion and lipid metabolism depends on inhibition of hepatic HNF4 $\boldsymbol{\alpha}$. (a-c) C57BL/6 mice were i.v. injected with Ad-empty or Ad-miR-34a $(n=6)$. Hepatic mRNA (a) and protein levels $(\mathbf{b}, \mathbf{c})$ were quantified. B100, ApoB100. B48, ApoB48. (d) VLDL secretion was determined in C57BL/6 mice after i.p. injection of Tyloxapol $\left(50 \mathrm{mg} \mathrm{kg}^{-1}\right)(n=6)$. (e-h) C57BL/6 mice were injected i.v. with Ad-empty, Ad-miR-34a, AdHNF $4 \alpha$ or Ad-miR-34a + Ad-HNF4 $\alpha(n=7)$. Hepatic protein levels (e) plasma TG (f) plasma cholesterol $(\mathbf{g})$ and hepatic TG levels (h) were determined. (i) HepG2 cells were transfected with a control mimic or miR-34a mimic, together with a pMIR-Report construct containing wild-type or mutant $3^{\prime}$ UTR of HNF4 $\alpha(n=4)$. After $36 \mathrm{~h}$, luciferase activity was determined and normalized to $\beta$-gal activity. MutA and mutB stand for the first or second mutant binding site for miR-34a, respectively. (j) Liver-specific $H n f 4 \alpha^{-/-}$mice were injected i.v. with Ad-HNF4 $\alpha-3^{\prime} U T R$ ( $\left.3^{\prime} U T R \_W T\right)$, Ad-HNF4 $\alpha-3^{\prime} U T R \_m u t A$ ( $\left.3^{\prime} U T R \_m u t A\right)$ or Ad-HNF4 $\alpha-3^{\prime} U T R \_m u t B$ (3'UTR_mutB) plus or minus Ad-miR-34a. After 7 days, hepatic protein levels were determined. $\mathrm{WT}=$ wild type. Values are expressed as mean \pm s.e.m. Two-sided Student's $t$-test was performed. ${ }^{\star} P<0.05,{ }^{\star}{ }^{\star} p<0.01$.

Hepatic HNF4 $\alpha$ regulates atherogenesis and energy metabolism. Loss-of-function mutations in $\mathrm{HNF} 4 \alpha$ cause hypolipidemia in MODY patients. So far, it is unknown whether MODY1 patients are protective against the development of atherosclerosis. Given that hepatic $\mathrm{HNF} 4 \alpha$ is markedly downregulated under various metabolic stress (Fig. 1), we investigated the effect of acute versus chronic loss of hepatic HNF4 $\alpha$ on the development of atherosclerosis. Acute knockdown of hepatic $H n f 4 \alpha$ by shRNA in Apoe ${ }^{-1-}$ mice for 3 weeks caused a $>50 \%$ reduction in plasma total cholesterol levels and an $\sim 30 \%$ reduction in plasma TG on a Western diet (Supplementary Fig. 9a-c). Analysis of plasma lipoprotein profiles by fast protein liquid chromatography (FPLC) indicated that loss of hepatic $H n f 4 \alpha$ reduced plasma VLDL cholesterol and LDL cholesterol (Fig. 4a) and VLDL TG (Fig. 4b). Consistent with the changes in plasma lipids and lipoproteins, acute knockdown of hepatic $H n f 4 \alpha$ in $A p o e^{-I-}$ mice reduced aortic lesion sizes by $>50 \%$ (Fig. $4 \mathrm{c}$ and Supplementary Fig. 9d). In addition, loss of hepatic $H n f 4 \alpha$ in $A p o e^{-/-}$mice increased hepatic TG accumulation (Fig. 4d) and reduced MTP and ApoB protein expression (Supplementary Fig. 9e). These data indicate that acute loss of hepatic HNF $4 \alpha$ reduces the development of atherosclerosis in Apoe $-1-$ mice.

To determine whether chronic loss of hepatic HNF4 $\alpha$ has a similar effect on atherosclerosis, we crossed $H N F 4 \alpha^{f l / f l}$ mice with $L d l r^{-1-}$ mice. These mice were then crossed with albumin-Cre mice to generate double-knockout (DKO) mice deficient in both $L d l r$ and hepatic $H n f 4 \alpha$ as well as control $\left(L d l r^{-I-} H N F 4 \alpha^{f l / f l}\right)$ mice. As compared with the control mice, the DKO mice had increased food intake (Supplementary Fig. 10a) but gained less body weight (Fig. 4e) and body fat content (Fig. 4f), and had increased $\mathrm{O}_{2}$ consumption and $\mathrm{CO}_{2}$ production (Fig. $4 \mathrm{~g}-\mathrm{i}$ ) as well as heat production (Fig. 4j). Mechanistically, DKO mice had increased Cpt1b expression in the liver (Supplementary Fig. 10b,c), suggesting that hepatic fatty acid oxidation may be increased in these mice. In addition, the DKO mice had a $>50 \%$ reduction in plasma cholesterol (Fig. 4k) and TG (Fig. 4l), and these changes were due to a marked reduction in plasma VLDL cholesterol and LDL cholesterol (Fig. 4m) and VLDL TG (Fig. 4n), respectively. In agreement with the change in plasma lipid profile, DKO mice had a $>50 \%$ reduction in the lesion size of aortic root (Fig. 4o,p), brachiocephalic artery (Fig. 4q) or aorta (Fig. 4r,s). Finally, consistent with a role of hepatic $\mathrm{HNF} 4 \alpha$ in controlling VLDL secretion, DKO mice had reduced VLDL secretion

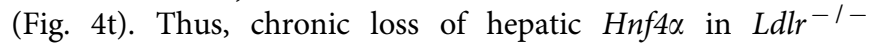
mice increases energy expenditure and protects against the development of atherosclerosis.

Hepatic miR-34a inhibits atherogenesis in $\mathrm{Ldlr}^{-/-}$mice. The finding that miR-34a regulates lipid metabolism through inhibition of HNF4 $\alpha$ (Fig. 3) led us to ask whether miR-34a also 
a

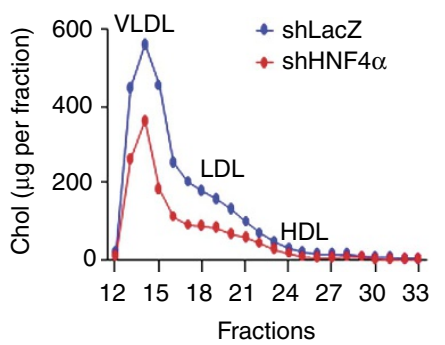

b

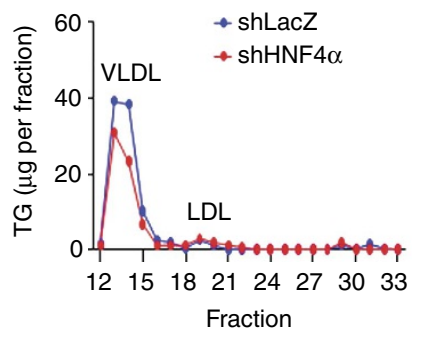

C

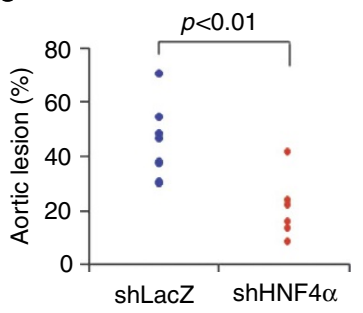

d

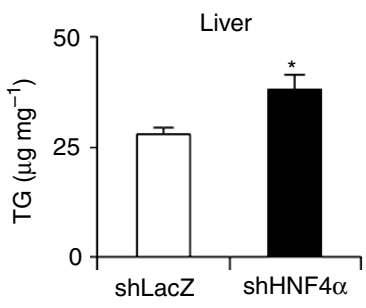

e

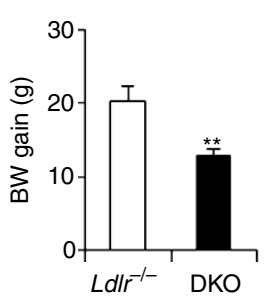

f

\section{g}

h

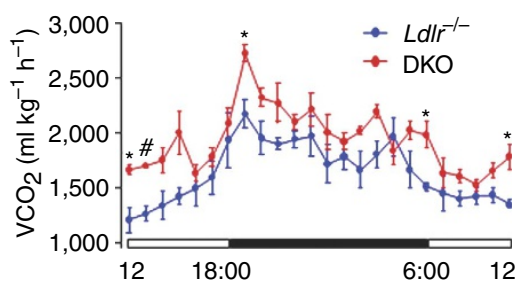

i

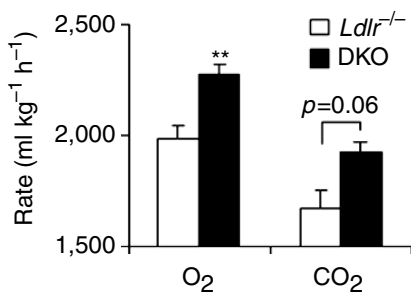

m

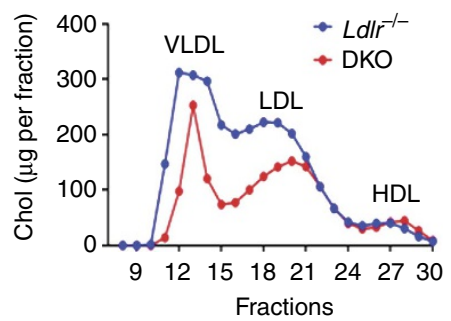

q

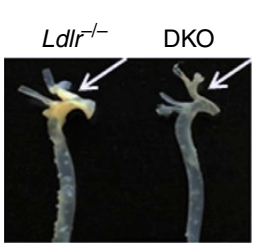

$r$

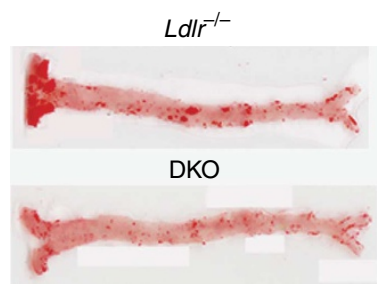

j

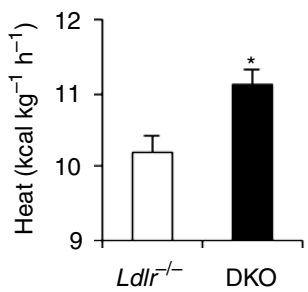

n

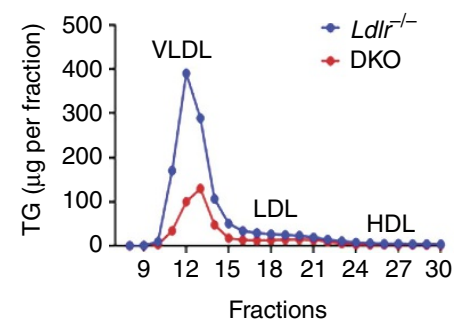

$\mathbf{S}$

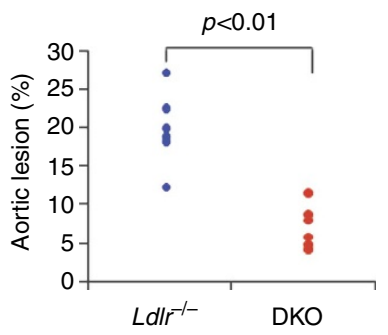

I

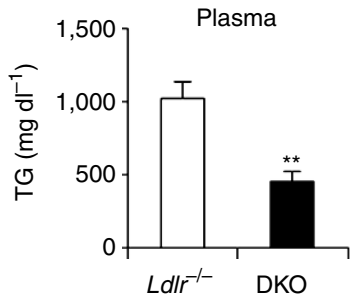

p

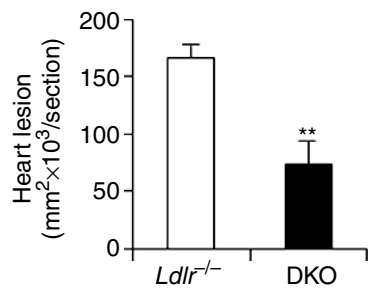

$\mathbf{t}$

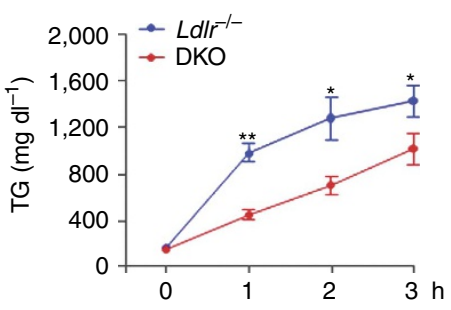

Figure 4 | Loss of hepatic HNF4 $\alpha$ improves energy homeostasis and protects against atherosclerosis. (a-d) Apoe ${ }^{-/-}$mice were fed a Western diet for 4 weeks, followed by injection of Ad-shLacZ or Ad-shHNF4 $\alpha(n=6)$. Three weeks following adenoviral injection, plasma cholesterol (a) and TG (b) lipoprotein profiles were determined. En face aortic lesion sizes were analysed (c) and hepatic TG levels quantified (d). (e-t) $H n f 4 \alpha^{f l / f l} L d l r^{-/-}\left(L d l r^{-/-}\right)$ mice and $H n f 4 \alpha^{f l / f l} A l b-C r e L d l r^{-/-}(D K O)$ mice were fed a Western diet for 16 weeks $(n=6)$. Body weight gain (e) and body fat content from gonadal (gon) fat, retroperitoneal (ret) fat and subcutaneous (sub) fat ( $\mathbf{f}$ ) were determined. $\mathrm{O}_{2}$ consumption ( $\left.\mathbf{g}, \mathbf{i}\right) \mathrm{CO}_{2}$ production (h,i) and heat production (j) were assessed by CLAMS. Plasma cholesterol (k) TG (I) cholesterol lipoprotein profile ( $\mathbf{m})$ and TG lipoprotein profile (n) were analysed. Aortic root was stained by oil red $\mathrm{O}(\mathbf{o})$ and lesion size quantified $(\mathbf{p})$. Aorta was isolated $(\mathbf{q})$ stained by oil red $\mathrm{O}(\mathbf{r})$ and the en face lesion size quantified $(\mathbf{s})$. VLDL secretion was performed when mice were fed a Western diet for 12 weeks ( $\mathbf{t})$. In (q) the arrow shows the location of the brachiocephalic artery. Scale bar, $200 \mu \mathrm{m}$. Values are expressed as mean \pm s.e.m. Two-sided Student's $t$-test was performed. ${ }^{\star} P<0.05,{ }^{\star \star} P<0.01$. 

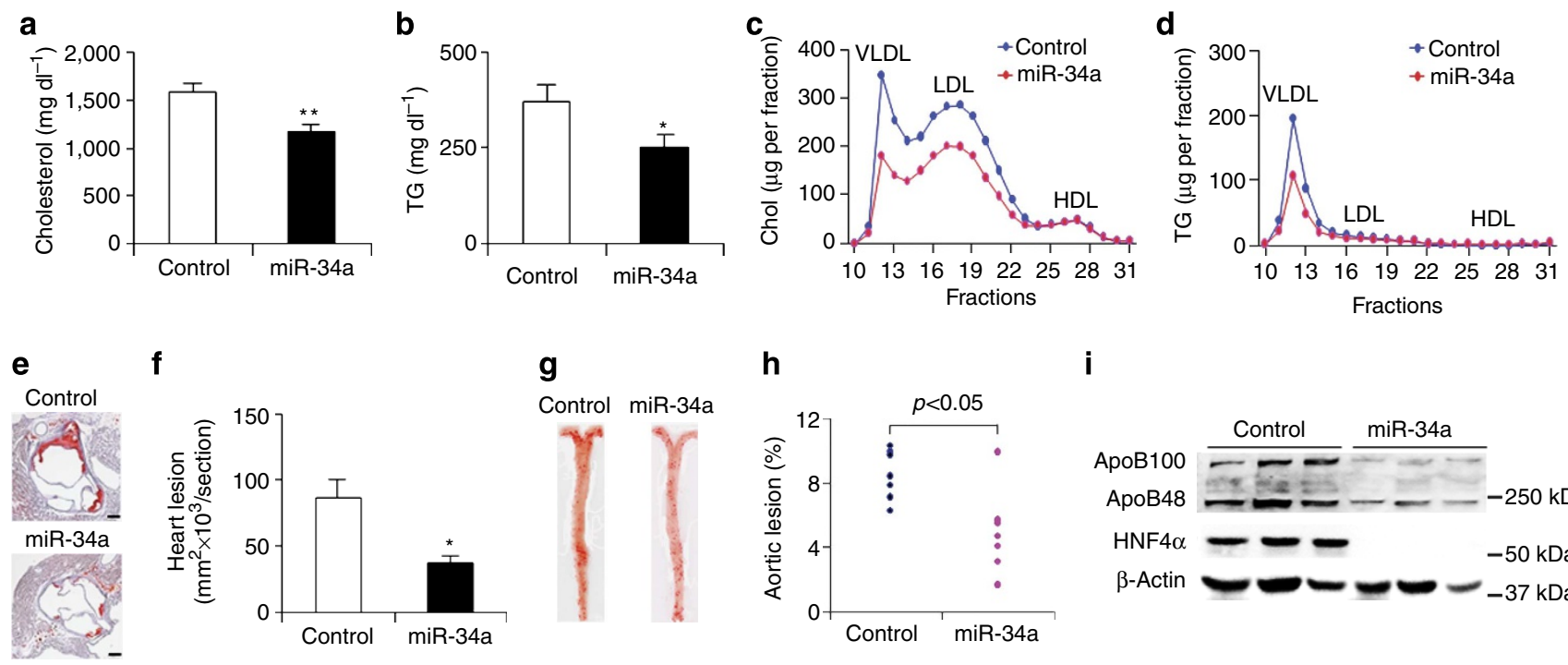

h

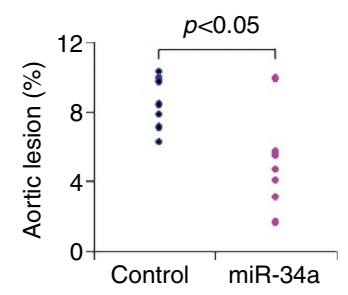

i

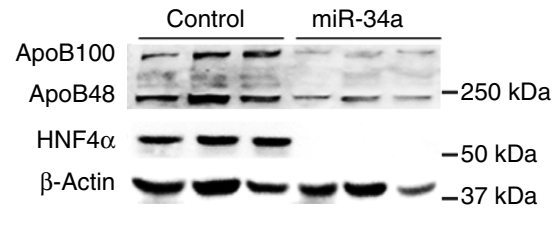

Figure 5 | miR-34a reduces the development of atherosclerosis in $\mathbf{L d} \mathbf{l} \mathbf{r}^{-\boldsymbol{I}} \mathbf{-}$ mice. $L d \mathbf{l} \mathbf{r}^{-/}$mice were fed a Western diet for a total of 7 weeks ( $n=6$ ). At the end of week 4, the mice were injected i.v. with Ad-empty or Ad-miR-34a. Plasma cholesterol (a) TG (b) cholesterol lipoprotein profile (c) and TG lipoprotein profile (d) were determined. Aortic root was stained by oil red $\mathrm{O}$ (e) and lesion size quantified (f). Aorta was also stained by oil red $\mathrm{O}$ ( $\mathbf{g}$ ) and the en face lesion size quantified (h). Hepatic protein levels were determined by western blot assays (i). Scale bar, $200 \mu \mathrm{m}$. Values are expressed as mean \pm s.e.m. Two-sided Student's $t$-test was performed. ${ }^{\star} P<0.05,{ }^{\star \star} P<0.01$.

regulates the development of atherosclerosis. Overexpression of miR-34a in Western diet-fed $L d l r^{-1-}$ mice reduced plasma total cholesterol (Fig. 5a) and TG levels (Fig. 5b). The data from FPLC analysis showed that miR-34a reduced the levels of VLDL and LDL cholesterol (Fig. 5c) as well as VLDL TG (Fig. 5d). As a result, overexpression of miR-34a in the liver reduced the atherosclerotic lesion size by $>50 \%$ in both the aortic root (Figs $5 \mathrm{e}, \mathrm{f}$ ) and aorta (Fig. 5g,h) of $\mathrm{Ldll}^{-1-}$ mice. In the liver, overexpression of miR-34a in $L d l r^{-1-}$ mice inhibited hepatic HNF4 $\alpha$, ApoB100 and ApoB48 expression (Fig. 5i) and increased hepatic TG levels (Supplementary Fig. 11). Thus, either overexpression of hepatic miR-34a (Fig. 5) or inhibition of hepatic HNF4 $\alpha$ (Fig. 4) can provide protection against the development of atherosclerosis.

p53 and FFAs regulate the miR-34a-HNF4 $\alpha$ pathway. The finding that the miR-34a-HNF4 $\alpha$ pathway is highly induced under common metabolic stress and regulates lipid and lipoprotein metabolism is quite intriguing. However, it remains to be determined which metabolic cue(s) trigger this pathway. p53 is an oxidative stress-inducible protein and is shown to both upregulate miR-34a expression ${ }^{26-29}$ and promote liver steatosis ${ }^{30,31}$. Indeed, nuclear p53 protein levels were induced by 6.7 -fold in NASH patients (Fig. 6a,b). Interestingly, p53 protein levels were unchanged in diabetic mice or HFD-induced mice (Supplementary Fig. 12a-c). Overexpression of p53 in HepG2 cells significantly induced miR-34a expression (Supplementary Fig. 13) and reduced HNF $4 \alpha$ protein level (Fig. 6c). The data of Fig. $6 a-c$, together with previous observations ${ }^{26-31}$, suggest that p53 may contribute to the induction of the miR-34a-HNF4 $\alpha$ pathway and liver steatosis in NASH patients.

Obesity, diabetes and insulin resistance are common risk factors for NAFLD, which is associated with higher levels of free fatty acids (FFAs), cholesterol, insulin and/or glucose in the blood and/ or tissues. Treatment of HepG2 cells with palmitate (Fig. 6d), linoleic acid (Fig. 6e), oleic acid (Fig. 6f) or cholesterol (Fig. 6g) significantly reduced HNF $4 \alpha$ expression (Fig. 6d-h). In contrast, insulin or glucose treatment had no effect on HNF4 $\alpha$ expression in
HepG2 cells (Supplementary Fig. 14a,b). Treatment with palmitate, linoleic acid or oleic acid also significantly increased miR-34a expression in HepG2 cells (Fig. 6i). Similar results were also observed when the murine primary hepatocytes were used (Supplementary Fig. 14c-e). Together, our data suggest that FFAs, cholesterol and p53 are upstream activators for the miR-34a-HNF4 $\alpha$ pathway in diabetes, obesity and NASH (Fig. 6j).

\section{Discussion}

NAFLD is one of the most common liver diseases worldwide. However, the underlying mechanism remains elusive. Here we report that a novel miR-34a-HNF4 $\alpha$ pathway regulates both hepatic TG levels and plasma lipid and lipoprotein metabolism. Given that this pathway is activated under common metabolic stress (diabetes, HFD feeding and NASH), this pathway may represent a common mechanism leading to the pathogenesis of human NAFLD. Targeting the miR-34a-HNF4 $\alpha$ pathway may be an attractive approach to treatment of NAFLD.

The finding that hepatic HNF4 $\alpha$ is markedly reduced in diabetes, obesity and NASH is quite intriguing. In NASH patients, hepatic HNF4 $\alpha$ protein is almost absent. Consistent with this finding, the vast majority of HNF $4 \alpha$ target genes, including those involved in bile acid metabolism, blood coagulation, lipid and lipoprotein metabolism, xenobiotic/drug metabolism and liver differentiation (HNF1 $\alpha$ ), are significantly reduced in NASH patients (Supplementary Table 1). Previous data show that HNF4 $\alpha$ also regulate genes involved in urea synthesis in mice ${ }^{32}$. We do not see any change in genes involved in urea synthesis in NASH patients, which could be due to the difference in species. In HFD-fed mice, hepatic HNF4 $\alpha$ protein is reduced only by $\sim 80 \%$. As a result, some of the known $H n f 4 \alpha$ target genes are also reduced, whereas some others remain unchanged in these mice (Supplementary Table 2). Other yet-to-be-determined factors may also contribute to the selective regulation of HNF4 $\alpha$ target genes in the HFD-fed mice.

Previous studies have shown that $m i R-34 a$ is induced in NAFLD patients 33,34 and obese/diabetic mice ${ }^{35,36}$. However, whether or how miR-34a regulates hepatic TG metabolism has 
a
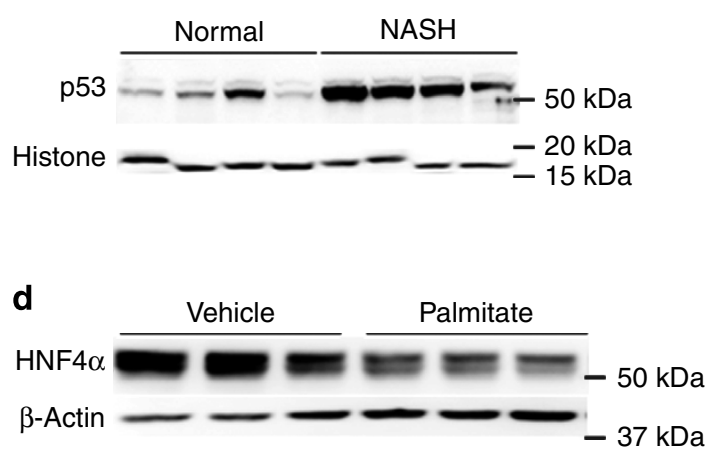

f

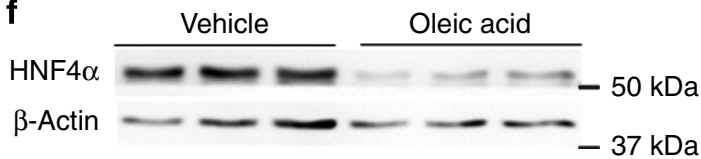

g

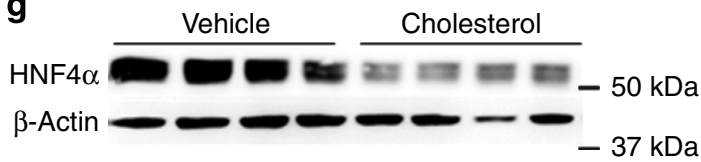

b

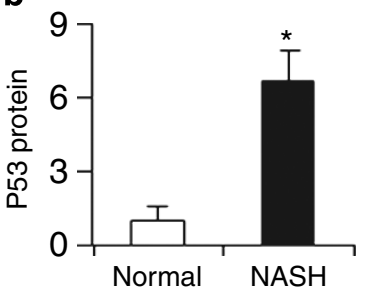

c

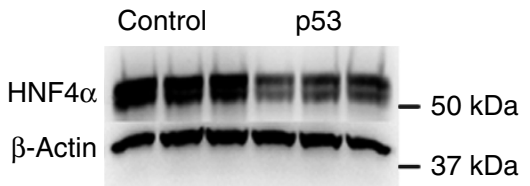

e

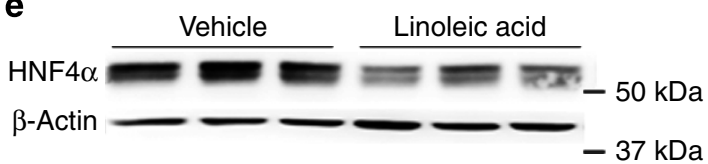

h

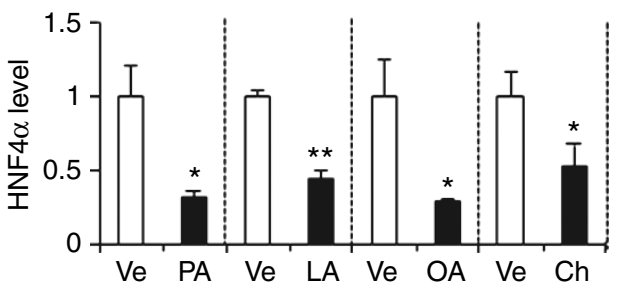

i

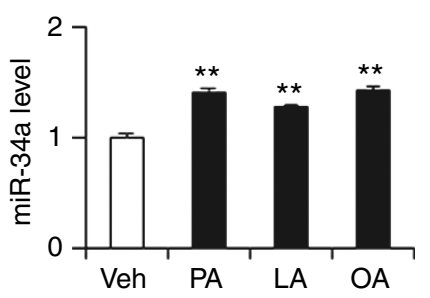

j Metabolic stress (HFD, diabetes, NASH)
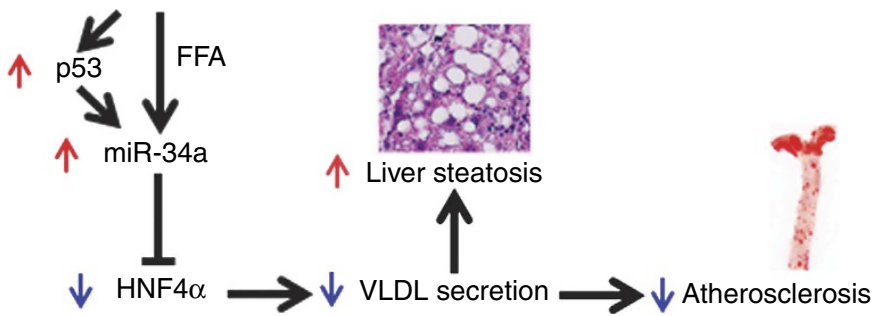

Figure 6 | p53, fatty acids and cholesterol regulate the miR-34a-HNF4 $\alpha$ pathway. $(\mathbf{a}, \mathbf{b})$ Nuclear p53 protein levels in the livers of normal individuals and NASH patients were determined by western blot assays (a) and then quantified (b). (c) HepG2 cells were infected with Ad-empty or Ad-p53. After 48 h, protein levels were determined by western blot assays. (d-i) HepG2 cells were treated with either vehicle (Ve), palmitate (PA; $300 \mu M)(\mathbf{d})$ linoleic acid $(\mathrm{LA} ; 300 \mu \mathrm{M})(\mathbf{e})$ oleic acid $(\mathrm{OA} ; 300 \mu \mathrm{M})(\mathbf{f})$ or cholesterol $\left(\mathrm{Ch} ; 10 \mu \mathrm{g} \mathrm{ml} \mathrm{l}^{-1}\right)(\mathbf{g})$. Western blot assays were performed (d-g) and then quantified (h). qRTPCR was used to quantify miR-34a levels (i). (j) Role of the miR-34a-HNF4 $\alpha$ pathway in regulating lipid and lipoprotein metabolism. Under metabolic stress, miR-34a is highly induced via both p53-dependent and -independent pathways. The induction of miR-34a causes a reduction in hepatic HNF4 $\alpha$ expression and VLDL secretion, leading to liver steatosis and inhibition of atherogenesis. Values are expressed as mean \pm s.e.m. Two-sided Student's $t$-test was performed. ${ }^{\star} P<0.05,{ }^{\star \star} P<0.01$.

not been addressed previously. Here we show that increased $m i R$ $34 a$ expression results in TG accumulation, whereas inhibition or ablation of $m i R-34 a$ expression reduces TG accumulation in both mice and HepG2 cells. By using human NASH patient samples and various diabetes and obesity mouse models, we conclude that miR-34a and HNF4 $\alpha$ are inversely regulated under all the common metabolic stress. Recently, Lamba et al. ${ }^{37}$ also observed a negative correlation between hepatic miR-34a and HNF4 $\alpha$ expression in humans, further supporting our finding. The finding that miR-34a inhibits HNF4 $\alpha$ expression has led us to hypothesize that miR-34a regulates hepatic TG levels via inhibition of $H N F 4 \alpha$. Such a hypothesis is validated by our subsequent studies. Our previous studies demonstrate that loss of hepatic HNF $4 \alpha$ has no effect on hepatic TG biosynthesis but causes liver steatosis by reducing VLDL secretion ${ }^{19}$. Consistent with our previous finding, miR-34a reduces VLDL secretion and has no effect on de novo lipogenesis (Supplementary Fig. 7). Thus, our current work not only reveals a novel function for miR-34a in regulating hepatic TG metabolism, but also elucidates how miR34 a regulates hepatic TG metabolism.

Choi et al ${ }^{38}$ reported that miR-34a also reduces $\mathrm{NAD}^{+}$levels and SIRT1 activity by targeting NAMPT, the rate-limiting enzyme of $\mathrm{NAD}^{+}$synthesis. Although SIRT1 is known to play an important role in metabolic control, including hepatic TG metabolism, it remains to be determined whether SIRT1 plays a role in miR-34a-regulated TG metabolism. According to our compelling data, miR-34a increases hepatic TG levels by inhibition of HNF $4 \alpha$. Interestingly, overexpression of miR-34a selectively regulates some of the HNF $4 \alpha$ target genes (Fig. 3), which could result from incomplete inhibition of $\mathrm{HNF} 4 \alpha$ expression and $\mathrm{HNF} 4 \alpha$-independent gene regulation.

Another important finding of this study is that we demonstrate that the miR-34a-HNF4 $\alpha$ pathway also regulates plasma ApoBcontaining lipoprotein metabolism and the development of atherosclerosis. Increased plasma levels of ApoB-containing lipoproteins are known to accelerate the development of 
atherosclerosis. Our data show that the miR-34a-HNF4 $\alpha$ pathway promotes hypolipidemia by inhibition of VLDL secretion. In line with this finding, it has been reported that NASH patients have reduced VLDL secretion ${ }^{39}$. As a result of the hypolipidemia, either overexpression of miR-34a or inhibition/ablation of hepatic $H n f 4 \alpha$ expression prevents the development of atherosclerosis in Apoe ${ }^{-1-}$ mice or $\mathrm{Ldlr}^{-1-}$ mice. These data provide the first evidence demonstrating that the miR-34a-HNF4 $\alpha$ pathway regulates the development of atherosclerosis. On the basis of our studies, it will be interesting to investigate whether NASH patients and/or MODY1 patients are protective against atherosclerosis.

In addition to elucidating the role of the miR-34a-HNF4 $\alpha$ pathway in regulating lipid and lipoprotein metabolism, we also investigated how this pathway is activated under common metabolic stress. Our data suggest that the miR-34a-HNF4 $\alpha$ pathway is activated in both p53-dependent and p53-independent manners (Fig. 6j). In NASH patients, p53, FFAs and cholesterol may work together to activate the miR-34a-HNF4 $\alpha$ pathway. However, p53 is not activated in diabetes or HFD-induced obesity. Thus, under these latter conditions, FFAs and cholesterol may be the major factors triggering activation of the miR-34aHNF $4 \alpha$ pathway. One of our future directions will be to investigate how FFAs and cholesterol activate the miR-34aHNF4 $\alpha$ pathway and whether other metabolic cues are also involved in regulation of this pathway.

In summary, the current study has demonstrated that the metabolic stress-inducible miR-34a-HNF $4 \alpha$ pathway may play a critical role in both the pathogenesis of NAFLD and regulating plasma lipid and lipoprotein metabolism. Although loss of hepatic HNF4 $\alpha$ has a beneficial effect on atherosclerosis and energy homeostasis, loss of hepatic HNF4 $\alpha$ causes fatty liver by inhibiting VLDL secretion. Thus, from therapeutic standpoint, suppression of hepatic HNF4 $\alpha$ expression together with approaches that alleviate hepatic steatosis may be useful for preventing the development of atherosclerosis. In contrast, overexpression of hepatic HNF $4 \alpha$ does not have much effect on plasma lipid or lipoprotein metabolism likely because HNF4 $\alpha$ is one of the most abundant genes in the liver ${ }^{19}$. Given that HNF4 $\alpha$ expression is markedly reduced under metabolic stress (diabetes, HFD feeding and NASH), delivery of HNF4 $\alpha$ via adenoassociated virus or other gene therapy vehicle(s) is a feasible and attractive approach to prevention and treatment of NAFLD associated with metabolic syndrome. In addition, antagonism of hepatic miR-34a function by antagomir(s) is also a feasible approach that may help prevent the development of NAFLD. Thus, targeting the miR-34a-HNF4 $\alpha$ pathway represents a promising and attractive approach for treatment of human NAFLD.

\section{Methods}

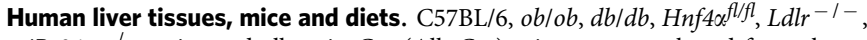
$m i R-34 a^{-1-}$ mice and albumin-Cre (Alb-Cre) mice were purchased from the Jackson Laboratories (Bar Harbor, Maine). Hnf4 $\alpha^{f l / f l}$ mice were crossed with $L d l r^{-I-}$ mice to produce $H n f 4 \alpha^{f l / f l} L d l r^{-1}$ mice, which were subsequently crossed with Alb-Cre mice to produce liver-specific $H n f 4 \alpha^{-I} L d l r^{-}-$

$\left(L-H n f 4 \alpha^{-/-} L d l r^{-/-}\right)$mice. For streptozotocin (STZ) treatment, C57BL/6J mice were injected intraperitoneally (i.p.) with either vehicle $(0.1 \mathrm{M}$ sodium citrate, $\mathrm{pH} 4.5)$ or STZ $\left(50 \mathrm{mg} \mathrm{kg}^{-1}\right)$ for 5 days and then killed 5 weeks after the treatment. For HFD feeding, C57BL/6J mice were fed a chow diet or an HFD (60\% kcal from fat; Research Diets, New Brunswick, NJ, USA) for 16 weeks. For HFHC diet feeding, C57BL/6J mice were fed a chow diet or an HFHC diet ( $42 \% \mathrm{kcal}$ fat $/ 0.2 \%$ cholesterol; Harlan Teklad, Madison, Wisconsin, USA) for 3 weeks. Unless otherwise stated, male and age-matched (8-12 weeks old) mice were randomly assigned to groups and all mice were fasted for 5-6 h before being killed. Mice that did not look healthy were excluded in the studies. Human liver samples were obtained from the Liver Tissue Cell Distribution System at University of Minnesota. Both male and female individuals were included. The average ages for normal individuals and NASH patients were 55.8 and 52.5 year old, respectively.
Individuals with alcohol drinking history (2-3 drinks/day) and liver cancer were excluded from the study. All the animal experiments were approved by the Institutional Animal Care and Use Committee at Northeast Ohio Medical University (NEOMED) and the use of human tissue samples were approved by the Institutional Review Board at NEOMED.

Mutagenesis, transfections and cell culture. HepG2 cells were purchased from ATCC (Virginia) and cultured in DMEM plus $10 \%$ FBS. $3^{\prime}$-UTR of mouse $H n f 4 \alpha$ was cloned to the Mlu/PmeI sites of pMIR-Report (catalogue AM5795, Life Technologies). Potential miR-34a binding site A (232-238 nt) and site B (2710$2716 \mathrm{nt}$ ) were mutated using a mutagenesis kit from Agilent (catalogue 210518). The forward primer sequences for the mutant binding site A (mutA) and the mutant binding site $\mathrm{B}$ (mutB) are $5^{\prime}$-gagaagaccccagggaggactgtcttcggtctagtggac tcctctcaagttgaagtcatcgtc- $3^{\prime}$ and $5^{\prime}$-cctaccctgatccccaaggccccaccatggtctagcaaggggg taaaaaagagaaaaagcctc- $3^{\prime}$, respectively (mutations are indicated in bold). An miR34a mimic (C-310529-07-0005) and a control mimic were purchased from Dhmarcon (Thermo Scientific). Transfections were performed using Lipofectamin 2000 (catalogue 11668019, Life Technologies). The miRNA mimics were transfected at a final concentration of $50 \mathrm{nM}$. For treatment with FAs or cholesterol HepG2 cells or primary hepatocytes were cultured in serum-free DMEM, then treated with either vehicle or palmitate $(300 \mu \mathrm{M})$, oleic acid $(300 \mu \mathrm{M})$, linoleic acid $(300 \mu \mathrm{M})$ or cholesterol $\left(10 \mu \mathrm{g} \mathrm{ml}^{-1}\right)$. Cells were harvested $48-72 \mathrm{~h}$ later for luciferase or western blot assays or lipid extraction.

Adenoviruses. Ad-shLacZ, Ad-HNF $4 \alpha$, Ad-shHNF $4 \alpha$, Ad-empty (control) and Ad-miR-34a have been described previously ${ }^{19,35}$. When Ad-HNF4 $\alpha$ was constructed, only the $H n f 4 \alpha$ coding region (which does not include any $3^{\prime} \mathrm{UTR}$ ) was cloned into the adenoviral vector. In contrast, Ad-HNF $4 \alpha-3^{\prime} \mathrm{UTR}$, Ad-HNF $4 \alpha-$ $3^{\prime} \mathrm{UTR} \_$mutA and Ad-HNF4 $\alpha-3^{\prime} \mathrm{UTR} \_$mutB were generated by cloning the Hnf $4 \alpha$ coding region plus wild type or mutant $3^{\prime} \mathrm{UTR}$ (with mutA or mutB) into a pAd/ CMV/V5-Dest vector (catalogue V493-20, Life Technologies), followed by transfection into 293 cells for adenovirus production ${ }^{40}$. Ad-p53 was purchased from Vector Biolabs (cat \# 1168). Ad-anti-miR-34a was generated by Applied Biological Materials (British Columbia, Canada). Cells were infected with adenoviruses at a multiplicity of infection (MOI) of 5. Mice were intravenously (i.v.) injected with $0.5-1.5 \times 10^{9}$ p.f.u. adenoviruses. Unless otherwise stated, the mice were killed 7 days post infection.

Real-time PCR. RNA was isolated using TRIzol Reagent (Life Technologies, CA) miRNAs were isolated using mirVana miRNA isolation kit (Life Technologies, CA). mRNA levels were determined by quantitative reverse-transcription polymerase chain reaction (qRT-PCR) on a 7500 real-time PCR machine from Applied Biosystems (Foster City, CA) by using SYBR Green Supermix (Roche, Indianapolis, IN). Results were calculated using $C t$ values and normalized to $36 B 4 \mathrm{mRNA}$ level. miRNA levels were quantified using TaqMan primers and probes (Catalogue 4427975, Life Technologies, CA) and normalized to U6 levels.

MicroRNA Northern blot assays. MicroRNA levels were also determined by Northern blot assays following the manufacturer's instructions (Signosis, Santa Clara, CA. Cat \# NB-1001). In the Northern blot assays, robes for miR-34a (Catalogue MP-0602) and U6 (Catalogue MP-0512) were also from Signosis.

MTP activity assays. Liver was homogenized and MTP activity was measured following the manufacturer's instructions (Chylos, Inc, Woodbury, NY. Cat \#R100).

Western blot assays. Western blot assays were performed using whole-liver lysates $^{41}$ or nuclear proteins of the liver samples and images were collected by ImageQuant LAS 4000 (GE Healthcare, Pittsburgh, PA) ${ }^{42}$. MTP antibody (catalogue sc-135994), HNF4 $\alpha$ antibody (catalogue sc-6556) and p53 antibody (catalogue sc-6243) were purchased from Santa Cruz Biotechnology (Santa Cruz, CA). ApoB antibody was purchased from Meridian Life Science (K45253G, TN). $\beta$-actin antibody was from Novus Biologicals (catalogue NB600-501, CO). Histone antibody was from Cell Signaling (Beverly, MA). The antibodies were used at a concentration of $1 \mu \mathrm{g} \mathrm{ml}^{-1}$.

Antagomirs. miR-34a LNA inhibitor/antagomir (LNA-miR-34a; anta-miR-34a; anta-34a) and miRNA scramble LNA inhibitor/antagomir (LNA-scr; anta-scr) were synthesized by Exiqon (Denmark, Cat \# 199900). ob/ob mice or HFD-fed mice (fed an HF diet for 12 weeks) were injected i.v. with either anta-miR-34a or anta-scr once every 6 days $\left(10 \mathrm{mg} \mathrm{kg}^{-1}\right)$. After three injections, mice were killed.

Lipid and lipoprotein analysis. Approximately $100 \mathrm{mg}$ liver was homogenized in methanol and lipids were extracted in chloroform/methanol $(2: 1 \mathrm{v} / \mathrm{v})$ as described $^{43}$. Hepatic triglyceride and cholesterol levels were then quantified using Infinity reagents from Thermo Scientific (Waltham, MA). Plasma lipid and glucose levels 
were also determined using Infinity reagents. Plasma lipoprotein profile was analysed by FPLC as described ${ }^{19}$. In brief, after $100 \mu \mathrm{l}$ plasma was injected, lipoproteins were run at $0.5 \mathrm{ml} \mathrm{min}-1$ in a buffer containing $0.15 \mathrm{M} \mathrm{NaCl}, 0.01 \mathrm{M}$ $\mathrm{Na}_{2} \mathrm{HPO} 4,0.1 \mathrm{mM}$ EDTA, pH 7.5, and separated on a Superose $610 / 300 \mathrm{GL}$ column (GE Healthcare) by using BioLogic DuoFlow QuadTec 10 System (Bio-Rad, CA). Five hundred microlitres of sample per fraction was collected.

VLDL secretion. C57BL/6J mice were injected intravenously with specific adenoviruses. On day 6 , these mice were fasted overnight, followed by intravenous injection of Tyloxapol $\left(500 \mathrm{mg} \mathrm{kg}^{-1}\right)$. Blood was taken at indicated time points and plasma TG levels determined.

De novo lipogenesis. Mice were injected i.p. with heavy water $\left({ }^{2} \mathrm{H}_{2} \mathrm{O}\right)$ to reach $3 \%$ enrichment. After $4 \mathrm{~h}$, livers were collected. Labelled and unlabelled palmitate, glycerol (triglycerides) and cholesterol were analysed by mass spectrometry ${ }^{19,44}$.

Atherosclerotic lesions. The aorta and aortic root were isolated and dissected. The aortic root was washed with phosphate-buffered saline, embedded in optimal cutting temperature compound, and then frozen on dry ice. Serial $7-\mu \mathrm{m}$-thick cryosections from the middle portion of the ventricle to the aortic arch were collected on superfrost plus microscope slides (Catalogue 12-550-15, Fisher Scientific). In the region beginning at the aortic valves, every other section was collected. Sectioned aortic root or en face aorta was stained with oil red $\mathrm{O}$ and the atherosclerotic lesion size determined using Image-Pro Premier 9.0 (Media Cybernetics, Rockville, MD) $)^{45}$.

Energy expenditure. Mice fed a Western diet were put in the Comprehensive Lab Animal Monitoring System (CLAMS). Oxygen consumption, $\mathrm{CO}_{2}$ production and heat production were determined ${ }^{46}$. In brief, mice were put in the acclimation cages for $40-48 \mathrm{~h}$. After the acclimation period, mice were weighed and placed back into the acclimation cage with pre-weighed food. Gas exchange was measured in mice every $30 \mathrm{~s}$. Room air was pumped into the mouse calorimetry cages at $0.472-0.600$ liters per minute (LPM) and cage air was sampled at 0.4 LPM. Physical activity was measured simultaneously using 16 infrared sensors spread over $19 \mathrm{~cm}$. Data from noon on day 1 to noon on day 2 (EST) were selected for analysis.

Statistical analysis. Statistical significance was analysed using unpaired twosided Student's $t$-test or ANOVA (GraphPad Prisim, CA). All values are expressed as mean \pm s.e.m. Differences were considered statistically significant at $P<0.05$

\section{References}

1. Petersen, K. F. et al. Reversal of nonalcoholic hepatic steatosis, hepatic insulin resistance, and hyperglycemia by moderate weight reduction in patients with type 2 diabetes. Diabetes 54, 603-608 (2005).

2. Yki-Jarvinen, H. Fat in the liver and insulin resistance. Ann. Med. 37, 347-356 (2005)

3. Anstee, Q. M. \& Goldin, R. D. Mouse models in non-alcoholic fatty liver disease and steatohepatitis research. Int. J. Exp. Pathol. 87, 1-16 (2006).

4. Angulo, P. Nonalcoholic fatty liver disease. N. Engl. J. Med. 346, 1221-1231 (2002).

5. Li, Y., Jadhav, K. \& Zhang, Y. Bile acid receptors in non-alcoholic fatty liver disease. Biochem. Pharmacol. 86, 1517-1524 (2013).

6. Day, C. P. \& James, O. F. Steatohepatitis: a tale of two 'hits'? Gastroenterology 114, 842-845 (1998).

7. Farrell, G. C. \& Larter, C. Z. Nonalcoholic fatty liver disease: from steatosis to cirrhosis. Hepatology 43, S99-S112 (2006).

8. Angulo, P. Treatment of nonalcoholic fatty liver disease. Ann. Hepatol. 1, $12-19$ (2002).

9. Lewis, J. R. \& Mohanty, S. R. Nonalcoholic fatty liver disease: a review and update. Dig. Dis. Sci. 55, 560-578 (2010).

10. Drewes, T., Senkel, S., Holewa, B. \& Ryffel, G. U. Human hepatocyte nuclear factor 4 isoforms are encoded by distinct and differentially expressed genes. Mol. Cell Biol. 16, 925-931 (1996).

11. Jiang, S. et al. Expression and localization of P1 promoter-driven hepatocyte nuclear factor-4alpha (HNF4alpha) isoforms in human and rats. Nucl. Recept. 1, 5 (2003).

12. Dhe-Paganon, S., Duda, K., Iwamoto, M., Chi, Y. I. \& Shoelson, S. E. Crystal structure of the HNF4 alpha ligand binding domain in complex with endogenous fatty acid ligand. J. Biol. Chem. 277, 37973-37976 (2002).

13. Wisely, G. B. et al. Hepatocyte nuclear factor 4 is a transcription factor that constitutively binds fatty acids. Structure 10, 1225-1234 (2002).
14. Fajans, S. S., Bell, G. I. \& Polonsky, K. S. Molecular mechanisms and clinical pathophysiology of maturity-onset diabetes of the young. N. Engl. J. Med. 345, 971-980 (2001).

15. Miura, A. et al. Hepatocyte nuclear factor-4alpha is essential for glucosestimulated insulin secretion by pancreatic beta-cells. J. Biol. Chem. 281, 5246-5257 (2006).

16. Lehto, M. et al. Mutation in the HNF-4alpha gene affects insulin secretion and triglyceride metabolism. Diabetes 48, 423-425 (1999).

17. Shih, D. Q. et al. Genotype/phenotype relationships in HNF-4alpha/MODY1: haploinsufficiency is associated with reduced apolipoprotein (AII), apolipoprotein (CIII), lipoprotein(a), and triglyceride levels. Diabetes 49, 832-837 (2000).

18. Pramfalk, C. et al. Control of ACAT2 liver expression by HNF4\{alpha\}: lesson from MODY1 patients. Arterioscler. Thromb. Vasc. Biol. 29, 1235-1241 (2009).

19. Yin, L., Ma, H., Ge, X., Edwards, P. A. \& Zhang, Y. Hepatic hepatocyte nuclear factor 4alpha is essential for maintaining triglyceride and cholesterol homeostasis. Arterioscler. Thromb. Vasc. Biol. 31, 328-336 (2011).

20. Hayhurst, G. P., Lee, Y. H., Lambert, G., Ward, J. M. \& Gonzalez, F. J. Hepatocyte nuclear factor 4alpha (nuclear receptor 2A1) is essential for maintenance of hepatic gene expression and lipid homeostasis. Mol. Cell Biol. 21, 1393-1403 (2001).

21. Fernandez-Hernando, C., Suarez, Y., Rayner, K. J. \& Moore, K. J. MicroRNAs in lipid metabolism. Curr. Opin. Lipidol. 22, 86-92 (2011).

22. Sacco, J. \& Adeli, K. MicroRNAs: emerging roles in lipid and lipoprotein metabolism. Curr. Opin. Lipidol. 23, 220-225 (2012).

23. Soh, J., Iqbal, J., Queiroz, J., Fernandez-Hernando, C. \& Hussain, M. M. MicroRNA-30c reduces hyperlipidemia and atherosclerosis in mice by decreasing lipid synthesis and lipoprotein secretion. Nat. Med. 19, 892-900 (2013).

24. Cheung, O. \& Sanyal, A. J. Role of microRNAs in non-alcoholic steatohepatitis. Curr. Pharm. Des. 16, 1952-1957 (2010).

25. Rottiers, V. \& Naar, A. M. MicroRNAs in metabolism and metabolic disorders. Nat. Rev. Mol. Cell Biol. 13, 239-250 (2012).

26. Raver-Shapira, N. et al. Transcriptional activation of miR-34a contributes to p53-mediated apoptosis. Mol. Cell 26, 731-743 (2007).

27. Chang, T. C. et al. Transactivation of miR-34a by p53 broadly influences gene expression and promotes apoptosis. Mol. Cell 26, 745-752 (2007).

28. Tarasov, V. et al. Differential regulation of microRNAs by $\mathrm{p} 53$ revealed by massively parallel sequencing: miR-34a is a p53 target that induces apoptosis and G1-arrest. Cell Cycle 6, 1586-1593 (2007).

29. He, L. et al. A microRNA component of the p53 tumour suppressor network. Nature 447, 1130-1134 (2007).

30. Derdak, Z. et al. Inhibition of p53 attenuates steatosis and liver injury in a mouse model of non-alcoholic fatty liver disease. J. Hepatol. 58, 785-791 (2013).

31. Yahagi, N. et al. p53 involvement in the pathogenesis of fatty liver disease. J. Biol. Chem. 279, 20571-20575 (2004).

32. Inoue, Y., Hayhurst, G. P., Inoue, J., Mori, M. \& Gonzalez, F. J. Defective ureagenesis in mice carrying a liver-specific disruption of hepatocyte nuclear factor 4alpha (HNF4alpha ). HNF4alpha regulates ornithine transcarbamylase in vivo. J. Biol. Chem. 277, 25257-25265 (2002).

33. Cheung, O. et al. Nonalcoholic steatohepatitis is associated with altered hepatic MicroRNA expression. Hepatology 48, 1810-1820 (2008).

34. Cermelli, S., Ruggieri, A., Marrero, J. A., Ioannou, G. N. \& Beretta, L. Circulating microRNAs in patients with chronic hepatitis $\mathrm{C}$ and non-alcoholic fatty liver disease. PloS ONE 6, e23937 (2011).

35. Lee, J. et al. A pathway involving farnesoid $\mathrm{X}$ receptor and small heterodimer partner positively regulates hepatic sirtuin 1 levels via microRNA-34a inhibition. J. Biol. Chem. 285, 12604-12611 (2010).

36. Trajkovski, M. et al. MicroRNAs 103 and 107 regulate insulin sensitivity. Nature 474, 649-653 (2011).

37. Lamba, V., Ghodke, Y., Guan, W. \& Tracy, T. S. microRNA-34a is associated with expression of key hepatic transcription factors and cytochromes P450. Biochem. Biophys. Res. Commun. 445, 404-411 (2014).

38. Choi, S. E. et al. Elevated microRNA-34a in obesity reduces NAD + levels and SIRT1 activity by directly targeting NAMPT. Aging Cell 12, 1062-1072 (2013).

39. Charlton, M., Sreekumar, R., Rasmussen, D., Lindor, K. \& Nair, K. S. Apolipoprotein synthesis in nonalcoholic steatohepatitis. Hepatology 35 898-904 (2002).

40. Ge, X. et al. Aldo-keto reductase 1B7 is a target gene of FXR and regulates lipid and glucose homeostasis. J. Lipid Res. 52, 1561-1568 (2011).

41. Zhang, Y. et al. Activation of the nuclear receptor FXR improves hyperglycemia and hyperlipidemia in diabetic mice. Proc. Natl Acad. Sci. USA 103, 1006-1011 (2006). 
42. Zhang, Y., Yin, L. \& Hillgartner, F. B. SREBP-1 integrates the actions of thyroid hormone, insulin, cAMP, and medium-chain fatty acids on ACCalpha transcription in hepatocytes. J. Lipid Res. 44, 356-368 (2003).

43. Bligh, E. G. \& Dyer, W. J. A rapid method of total lipid extraction and purification. Can. J. Biochem. Physiol. 37, 911-917 (1959).

44. Xu, J. et al. Hepatic carboxylesterase 1 is essential for both normal and farnesoid $\mathrm{X}$ receptor-controlled lipid homeostasis. Hepatology 59, 1761-1771 (2014).

45. Zhang, Y. et al. FXR deficiency causes reduced atherosclerosis in Ldlr-/- mice. Arterioscler. Thromb. Vasc. Biol. 26, 2316-2321 (2006).

46. Zhang, Y. et al. Loss of FXR protects against diet-induced obesity and accelerates liver carcinogenesis in ob/ob mice. Mol. Endocrinol. 26, 272-280 (2012).

\section{Acknowledgements}

This work was supported by NIH grants R15DK088733, R01HL103227, R01DK095895 and R01DK102619 to Y.Z. Normal or pathologic human liver tissues were obtained through the Liver Tissue Cell Distribution System, Minneapolis, Minnesota, which was funded by NIH Contract \# HHSN276201200017C.

\section{Author contributions}

Y. X. and M.Z. designed and performed the study and analysed the data. J.X., Y.L. and L.Y. performed the study. Y.Z. designed and performed the study, analysed the data and wrote the paper.

\section{Additional information}

Supplementary Information accompanies this paper at http://www.nature.com/ naturecommunications

Competing financial interests: The authors declare no competing financial interests.

Reprints and permission information is available online at http://npg.nature.com/ reprintsandpermissions/

How to cite this article: Xu Y. et al. A metabolic stress-inducible miR-34a-HNF4 $\alpha$ pathway regulates lipid and lipoprotein metabolism. Nat. Commun. 6:7466 doi: $10.1038 /$ ncomms8466 (2015) 